\title{
MINIMISASI STASIUN PEMADAM KEBAKARAN DI KOTA PADANG
}

\author{
FAISAL ASRA, SUSILA BAHRI, NOVA NOLIZA BAKAR \\ Program Studi Matematika, \\ Fakultas Matematika dan Ilmu Pengetahuan Alam, Universitas Andalas, \\ Kampus UNAND Limau Manis Padang, Indonesia. \\ faisal02asra@yahoo.co.id
}

\begin{abstract}
Abstrak. Penelitian ini membahas tentang bagaimana menentukan jumlah minimum stasiun pemadam kebakaran yang harus tersedia untuk melayani kebakaran pada 11 kecamatan di Kota Padang. Model minimisasi stasiun pemadam kebakaran dibangun dengan menggunakan data waktu maksimum yang diperlukan oleh pemadam kebakaran. Selanjutnya, solusi model diperoleh dengan menggunakan metode simpleks melalui penggunaan perangkat lunak MATLAB R2013a. Model minimisasi stasiun pemadam kebakaran ini memberikan hasil bahwa stasiun pemadam kebakaran sebaiknya dibangun di Kecamatan Lubuk Begalung dan di Kecamatan Kuranji.
\end{abstract}

Kata Kunci: Metode Simpleks, Minimisasi, MATLAB

\section{Pendahuluan}

Maraknya kebakaran yang terjadi akhir-akhir ini di Kota Padang, sebagaimana yang diberitakan di koran-koran seperti Padang Ekspres dan Singgalang, telah membuat ketenangan dan kenyamanan penduduk kota Padang terusik. Kebakaran dengan berbagai penyebab seperti arus pendek dan meledaknya kompor, mengharuskan setiap penduduk untuk lebih berhati-hati dan bertanggung jawab terhadap peristiwa kebakaran yang terjadi di lingkungannya. Namun demikian, tidak dapat dipungkiri bahwa kenyamanan di Kota Padang juga merupakan tanggung jawab Pemerintah Kota Padang.

Pemerintah Kota Padang melalui BPBD PK (Badan Penanggulangan Bencana Daerah Pemadam Kebakaran) yang terletak di Jalan Rasuna Said No 56 Kecamatan Padang Timur dan di Jalan Muhammad Hatta Kecamatan Kuranji, telah berusaha melayani pengaduan kebakaran dari penduduk kota Padang dengan sebaik-baiknya. Ini dapat dibuktikan dengan tersedianya mobil pemadam kebakaran sebanyak 11 unit, lengkap bersama personilnya. Pada kenyataannya, untuk mengatasi kebakaran agar tidak menyebar dengan cepat, tidak hanya ditentukan oleh banyak atau tersedianya mobil pemadam kebakaran, tetapi yang lebih penting adalah ketepatan dan kecepatan mobil pemadam kebakaran sampai di lokasi kejadian.

Pemerintah Kota Padang yang hanya memiliki dua stasiun pemadam kebakaran tesebut, ternyata sering menghadapi kendala atau masalah dalam mengatasi kebakaran, karena jauhnya jarak lokasi kejadian dengan kedua stasiun pemadam kebakaran. Kendala dari segi waktu yang dapat menggagalkan atau melambatkan 
usaha pemadaman tersebut, dapat diatasi dengan mengetahui berapa banyak minimum stasiun pemadam kebakaran yang harus ada dan kemudian membangun stasiun pemadam kebakaran tersebut di kecamatan yang tepat sehingga dapat mengatasi ataupun meminimumkan dampak dari kebakaran.

\section{Landasan teori}

\subsection{Pemrograman Linier}

Pemrograman linier merupakan alat yang digunakan untuk menyelesaikan masalahmasalah optimasi (maksimisasi atau minimisasi). Masalah pemrograman linier adalah suatu masalah optimasi yang memenuhi hal-hal berikut:

(1) Memaksimumkan atau meminimumkan suatu fungsi linier dari variabel keputusan (variabel yang menggambarkan keputusan yang dibuat). Fungsi yang dimaksimumkan atau diminimumkan tersebut dinamakan fungsi tujuan.

(2) Nilai-nilai dari variabel keputusan mestilah memenuhi sehimpunan kendala. Tiap kendala mestilah merupakan sebuah persamaan linier atau ketaksamaan linier.

(3) Batasan tanda berhubungan dengan tiap variabel. Untuk sebarang variabel $x_{j}$, maka batasan tanda mestilah non-negative $\left(x_{j} \geq 0\right)$ atau tak terbatas (unrestricted).

\subsection{Pemrograman Linier Bilangan Bulat}

Salah satu bagian dari pemograman linier adalah pemograman linier bilangan bulat. Bentuk umum pemograman linier bilangan bulat adalah [6]:

$$
\begin{aligned}
\text { Maksimumkan/Minimumkan } & \sum_{j=1}^{n} c_{j} x_{j}, \\
\text { Kendala } & \sum_{j=1}^{n} a_{i j} x_{j} \geq \leq b_{i}, i=1,2, \cdots, m, \\
& x_{j} \geq 0, x_{j} \in \mathbb{Z}, j=1,2, \cdots, n .
\end{aligned}
$$

Jika semua variabel harus bernilai 0 atau $1\left(x_{1}, x_{2}, \cdots, x_{j}=0\right.$ atau 1$)$, maka masalah pemrograman linier bilangan bulat disebut dengan masalah pemrograman linier bilangan bulat $0-1$ sedangkan jika nilai $b=1$, maka masalah tersebut disebut sebagai Masalah Himpunan Penutup (Set Covering Problem) [4].

\subsection{Masalah Himpunan Penutup}

Misalkan $\mathcal{S}_{\mathcal{K}}=\left\{S_{1}, S_{2}, \cdots, S_{n}\right\}$ adalah keluarga subhimpunan dari suatu himpunan $S=\{1,2, \cdots, m\}$. Himpunan penutup $S$ adalah suatu subkeluarga $S_{j}$ untuk $j \in \mathcal{K}$ dimana $\mathcal{K}=\{1,2, \cdots, n\}$ sedemikian hingga $S=\bigcup_{j \in \mathcal{K}} S_{j}$. Asumsikan bahwa tiap subhimpunan $S_{j}$ memiliki biaya $c_{j}$ yang merupakan bilangan bulat positif. Kemudian ditetapkan biaya penutup adalah jumlah dari biaya subhimpunan yang termasuk dalam penutup tersebut. Selanjutnya, masalah penentuan himpunan 
penutup dengan biaya minimum merupakan masalah pemrograman linier bilangan bulat dengan matriks $A=\left[a_{i j}\right]$ yang berukuran $m \times n$ dimana:

$$
a_{i j}= \begin{cases}1, & \text { jika } i \in S_{j}, \\ 0, & \text { selainnya. }\end{cases}
$$

serta menetapkan $x_{j}$ sebagai variabel bernilai 0 atau 1 menjadi masalah [2]:

$$
\begin{aligned}
\text { Minimumkan } & \sum_{j=1}^{n} c_{j} x_{j} \\
\text { Kendala } & \sum_{j=1}^{n} a_{i j} x_{j} \geq 1, i=1,2, \cdots, m, \\
& x_{j} \in\{0,1\}, j=1,2, \cdots, n .
\end{aligned}
$$

\subsection{Metode Simpleks}

Metode simpleks merupakan salah satu teknik penyelesaian dalam program linier yang digunakan sebagai teknik pengambilan keputusan dalam permasalahan yang berhubungan dengan pengalokasian sumber daya secara optimal. Metode simpleks digunakan untuk mencari nilai optimal dari pemrograman linier yang melibatkan banyak kendala dan banyak variabel (terdiri dari dua variabel atau lebih). Metode ini diperkenalkan oleh George B. Dantzig pada tahun 1947 dan telah diperbaiki oleh beberapa ahli. Penemuan metode simpleks ini merupakan lompatan besar dalam riset operasi dan digunakan sebagai prosedur penyelesaian dari setiap perangkat lunak komputer [5].

Sebelum menggunakan metode simpleks, maka terlebih dahulu masalah pemrograman linier yang akan diselesaikan harus diubah ke dalam bentuk model pemrograman linier. Setelah berbentuk suatu model pemrograman linier, maka model tersebut harus diubah lagi menjadi bentuk baku pemrograman linier. Baru setelah model menjadi bentuk baku, maka dapat diterapkan prosedur penyelesaian dengan algoritma simpleks.

\begin{tabular}{|c|c|c|c|l|c|c|c|c|c|c|}
\hline $\mathrm{VD}$ & $Z$ & $x_{1}$ & $x_{2}$ & $\cdots$ & $x_{n}$ & $s_{1}$ & $s_{2}$ & $\cdots$ & $s_{n}$ & $\mathrm{NK}$ \\
\hline$Z$ & 1 & $-c_{1}$ & $-c_{2}$ & $\cdots$ & $-c_{n}$ & 0 & 0 & $\cdots$ & 0 & 0 \\
\hline$s_{1}$ & 0 & $a_{11}$ & $a_{11}$ & $\cdots$ & $a_{1 n}$ & 1 & 0 & $\cdots$ & 0 & $b_{1}$ \\
\hline$s_{2}$ & 0 & $a_{21}$ & $a_{22}$ & $\cdots$ & $a_{2 n}$ & 0 & 0 & $\cdots$ & 0 & $b_{2}$ \\
\hline$\cdots$ & $\cdots$ & $\cdots$ & $\cdots$ & $\cdots$ & $\cdots$ & $\cdots$ & $\cdots$ & $\cdots$ & $\cdots$ & $\cdots$ \\
\hline$\cdots$ & $\cdots$ & $\cdots$ & $\cdots$ & $\cdots$ & $\cdots$ & $\cdots$ & $\cdots$ & $\cdots$ & $\cdots$ & $\cdots$ \\
\hline$\cdots$ & $\cdots$ & $\cdots$ & $\cdots$ & $\cdots$ & $\cdots$ & $\cdots$ & $\cdots$ & $\cdots$ & $\cdots$ & $\cdots$ \\
\hline$s_{m}$ & 0 & $a_{m 1}$ & $a_{m 2}$ & $\cdots$ & $a_{m n}$ & 0 & 0 & $\cdots$ & 1 & $b_{m}$ \\
\hline
\end{tabular}

Tabel 1. Tabel Awal Simpleks 
Keterangan:

$$
\begin{aligned}
V D & =\text { variabel dasar } \\
N K & =\text { nilai kanan persamaan, } \\
c_{n} & =\text { koefisien untuk setiap variabel fungsi tujuan, } \\
x_{n} & =\text { variabel keputusan ke-n, } \\
s_{m} & =\text { variabel slack ke-n, } \\
a_{m n} & =\text { kebutuhan sumber daya ke-m untuk setiap } x_{n}, \\
b_{m} & =\text { jumlah sumber daya yang tersedia. }
\end{aligned}
$$

Bentuk baku pemrograman linier memiliki ciri-ciri sebagai berikut:

(1) Setiap Kendala harus berada dalam bentuk persamaan dengan nilai kanan kendala tidak negatif.

(2) Setiap variabel tidak bernilai negatif.

(3) Fungsi tujuan dapat berupa memaksimumkan atau minimumkan.

\subsection{Pemrograman Linier dengan MATLAB}

MATLAB adalah sebuah perangkat lunak pada komputer yang mengandung fungsi linprog yang khusus disediakan untuk menyelesaikan masalah-masalah pemrograman linier. Penggunaan fungsi linprog terhadap masalah pemrograman linier yang merupakan model matematis dapat digunakan dengan terlebih dahulu menetapkan koefisien-koefisien yang terdapat pada bagian kiri pertidaksamaan pada kendala sebagai matriks dan nilai pada bagian kanan pertidaksamaan pada kendala sebagai vektor. Setelah mendefinisikan nilai a11, a12, ..., ajj sebagai nilai dari setiap elemen maktriks, maka suatu matriks $A$ dalam MATLAB dapat didefinisikan dengan

$$
\text { > A }=[a 11 \ldots a 1 j ; a 21 \ldots a 2 j ; \ldots ; a j 1 \ldots a j j] ;
$$

yang menunjukkan bahwa matriks $A$ memiliki ukuran $j \times j$. Kemudian setelah mendefinisikan nilai b1, b2, ..., bj merupakan nilai dari nilai kanan pada kendala, suatu vektor kolom $b$ dapat dinyatakan secara umum dengan

$$
>b=[b 1 ; b 2 ; \ldots ; b j] ;,
$$

vektor ini berukuran $j \times 1[3]$.

Pengaktifan metode simpleks pada perangkat lunak MATLAB yaitu:

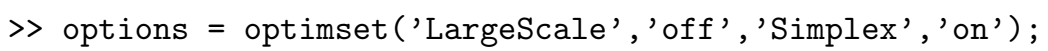

Pada sintaks di atas dapat dilihat bahwa metode dasar yang digunakan pada MATLAB metode interior-point digantikan dengan metode simpleks.

Selanjutnya bentuk umum pemanggilan fungsi linprog dengan kendala berbentuk ketidaksamaan adalah:

$$
\gg[x, f \min ]=\operatorname{linprog}(f, A, b,[],[], L B, U B,[], \text { options }) \text {; }
$$


dimana f, A, b, LB, UB, dan options merupakan input yang berturut-turut adalah fungsi tujuan yang akan diminimumkan, matriks kendala, jumlah sumber yang tersedia, batas bawah nilai variabel keputusan, batas atas nilai variabel keputusan, dan metode yang digunakan. Sedangkan variabel $\mathrm{x}$ dan fmin adalah variabelvariabel output.

\section{Pembahasan}

Kota Padang terdiri dari 11 (sebelas) kecamatan dengan urutan sebagai berikut:

(1) Kecamatan Bungus Teluk Kabung,

(2) Kecamatan Lubuk Kilangan,

(3) Kecamatan Lubuk Begalung,

(4) Kecamatan Padang Selatan,

(5) Kecamatan Padang Timur ( $\star$ ),

(6) Kecamatan Padang Barat,

(7) Kecamatan Padang Utara,

(8) Kecamatan Nanggalo,

(9) Kecamatan Kuranji $(\star)$,

(10) Kecamatan Pauh,

(11) Kecamatan Koto Tangah.

Tanda $\star$ menyatakan bahwa lokasi stasiun pemadam kebakaran pada saat ini terletak di Kecamatan Padang Timur dan di Kecamatan Kuranji. Untuk selanjutnya, setiap kecamatan dinotasikan dengan $k_{j}$ dengan $j=1,2, \cdots, 11$ yang merupakan urutan dari setiap kecamatan.

Data berikut adalah data waktu maksimum (dalam menit) yang diperlukan oleh mobil pemadam kebakaran (Damkar) bergerak dari suatu kecamatan ke kecamatan lainnya.

\begin{tabular}{|c|c|c|c|c|c|c|c|c|c|c|c|}
\hline & $k_{1}$ & $k_{2}$ & $k_{3}$ & $k_{4}$ & $k_{5}$ & $k_{6}$ & $k_{7}$ & $k_{8}$ & $k_{9}$ & $k_{10}$ & $k_{11}$ \\
\hline$k_{1}$ & 0 & 10 & 10 & 15 & 15 & 15 & 15 & 20 & 20 & 20 & 25 \\
\hline$k_{2}$ & 10 & 0 & 10 & 15 & 15 & 15 & 15 & 20 & 20 & 10 & 20 \\
\hline$k_{3}$ & 10 & 10 & 0 & 5 & 10 & 15 & 15 & 15 & 15 & 15 & 20 \\
\hline$k_{4}$ & 15 & 15 & 5 & 0 & 5 & 5 & 15 & 15 & 15 & 15 & 20 \\
\hline$k_{5}$ & 15 & 15 & 10 & 5 & 0 & 5 & 10 & 10 & 10 & 10 & 15 \\
\hline$k_{6}$ & 15 & 15 & 15 & 5 & 5 & 0 & 5 & 10 & 10 & 15 & 15 \\
\hline$k_{7}$ & 15 & 15 & 15 & 15 & 10 & 5 & 0 & 5 & 10 & 15 & 15 \\
\hline$k_{8}$ & 20 & 20 & 15 & 15 & 10 & 10 & 5 & 0 & 10 & 15 & 10 \\
\hline$k_{9}$ & 20 & 20 & 15 & 15 & 10 & 10 & 10 & 10 & 0 & 10 & 10 \\
\hline$k_{10}$ & 20 & 10 & 15 & 15 & 10 & 15 & 15 & 15 & 10 & 0 & 15 \\
\hline$k_{11}$ & 25 & 20 & 20 & 20 & 15 & 15 & 15 & 10 & 10 & 15 & 0 \\
\hline
\end{tabular}

Tabel 2. Data Waktu Maksimum yang Diperlukan Damkar 
Asumsi yang digunakan pada Tabel 2 adalah waktu yang diperlukan oleh Damkar untuk bergerak dari sebarang titik pada kecamatan tertentu ke sebarang titik pada kecamatan lain. Dengan syarat seperti titik tersebut memiliki jalan yang dapat dilalui oleh Damkar dan akses yang lancar untuk menuju ke kecamatan lainnya. Ini berarti jalur yang ditempuh oleh Damkar untuk menuju ke kecamatan lainnya tidak mengalami kemacetan, hambatan, dan gangguan. Pada pengolahan data diasumsikan bahwa kebakaran yang terjadi tidak boleh lebih dari satu kejadian pada waktu yang sama. Dari hasil wawancara dengan Bapak Suhardi (Kasi Operasi Pemadam) diperoleh bahwa waktu maksimum terbaik yang diperlukan pemadam kebakaran adalah 10 menit. Stasiun pemadam kebakaran pada dasarnya dapat ditempatkan pada sebarang kecamatan tersebut. Stasiun dengan unit mobil Damkarnya selain ditujukan untuk menangani kebakaran yang terjadi di kecamatan tempat stasiun tersebut berada, juga ditujukan untuk menangani kebakaran yang terjadi di kecamatan yang berada di lingkungannya. model minimisasi stasiun pemadam kebakaran sebagai berikut:

Minimumkan

$$
\begin{aligned}
& Z=x_{1}+x_{2}+x_{3}+x_{4}+x_{5}+x_{6}+x_{7}+x_{8}+x_{9}+x_{10}+x_{11} \text {, dengan kendala: } \\
& x_{1}+x_{2}+x_{3} \\
& x_{1}+x_{2}+x_{3} \\
& x_{1}+x_{2}+x_{3}+x_{4}+x_{5} \\
& x_{3} \quad+x_{4}+x_{5}+x_{6} \\
& x_{3}+x_{4}+x_{5}+x_{6}+x_{7}+x_{8}+x_{9}+x_{10} \\
& x_{4}+x_{5}+x_{6}+x_{7}+x_{8}+x_{9} \\
& x_{5}+x_{6}+x_{7}+x_{8}+x_{9} \\
& x_{5}+x_{6}+x_{7}+x_{8}+x_{9}+x_{11} \\
& x_{5}+x_{6}+x_{7}+x_{8}+x_{9}+x_{10}+x_{11} \\
& x_{2} \\
& +x_{5} \\
& +x_{9} \\
& x_{8} \quad+x_{9}
\end{aligned}
$$

dimana $x_{j} \in\{0,1\}$, untuk $j=1,2, \cdots, 11$.

Setelah menggunakan perangkat lunak MATLAB maka diperoleh hasil adalah $f_{\min }=2$ dan $x_{3}=x_{9}=1$. Secara berturut-turut menyatakan bahwa stasiun sebaiknya dibangun minimal dua stasiun dan terletak di Kecamatan Lubuk Begalung dan Kecamatan Kuranji.

\section{Kesimpulan}

Model pada penelitian ini dibangun dengan berdasarkan data waktu yang diperlukan oleh Damkar untuk bergerak dari sebarang titik pada kecamatan tertentu ke sebarang titik pada kecamatan lainnya dengan asumsi yaitu Damkar dalam perjalannya tidak mengalami kemacetan, hambatan, dan gangguan, dalam mengatasi kebakaran dan kebakaran yang terjadi tidak boleh lebih dari satu kejadian pada waktu yang sama.

Berdasarkan hasil yang diperoleh pada pembahasan, jumlah minimum stasiun pemadam kebakaran yaitu dua buah stasiun, telah dapat dipenuhi oleh pemerintah Kota Padang. Namun dari segi letaknya, hasil penelitian ini menyarankan 
supaya stasiun dibangun di Kecamatan Lubuk Begalung dan Kecamatan Kuranji agar pelayanan pemadam kebakaran dapat bekerja lebih optimal.

\section{Ucapan Terima kasih}

Penulis mengucapkan terima kasih kepada Bapak Dr. Mahdhivan, Bapak Narwen, M.Si dan Bapak Budi Rudianto, M.Si yang telah memberikan masukan dan saran dalam penyempurnaan penulisan artikel ini.

\section{Daftar Pustaka}

[1] Aminudin. 2005. Riset Operasi. Erlangga, Jakarta.

[2] Anonim. Tanpa tahun. http://www.doc.ic.ac.uk/br/berc/integerprog.pdf, diakses November 2014.

[3] Chinneck, J. W. 2004. Practical Optimization : A Gentle Introduction. http://www.sce.carleton.ca/fakulty/chinneck/po.html, diakses November 2014.

[4] Winston, W. L. 2004. Operations Research. University of Arizona, Arizona.

[5] Wirdasari, Dian. 2009. Metode Simpleks dalam Program Linier, J. SAINTIKOM 6(1): $276-285$

[6] Wosley, L. A. 1998. Integer Programming. John Wiley \& Sons, Chicago. 